\title{
AMÉRICA LATINA. ENTRE LA NUEVA REALIDAD Y LAS VIEJAS DESIGUALDADES
}

\author{
Marianela Acuña Ortigoza* \\ https://orcid.org/0000-0003-4934-6312
}

RECIBIDO: Octubre 2020 / ACEPTADO: Noviembre 2020 / PUBLICADO: Enero 2021

Como citar: Acuña Ortigoza, Marianela. (2021). América latina. Entre la nueva realidad y las viejas desigualdades. Telos: revista de Estudios Interdisciplinarios en Ciencias Sociales, 23 (1), Venezuela. (Pp. 129-140).

DOI: www.doi.org/10.36390/telos231.10

\section{RESUMEN}

Dialogar entre los que hacemos vida académica, compartimos pensares y haceres, es siempre un ejercicio de recreación espiritual, más que calificarnos intelectualmente, nos compromete la comprensión del ethos común. Con esa intención se proponen las reflexiones de este trabajo. Su objetivo es reconocer los nuevos sentidos que definen la realidad contemporánea en el contexto de la pandemia global del COVID-19, con énfasis analítico en América Latina, sus desigualdades y los efectos sobre la salud y la educación. Con base en Álvarez (2020), BonillaMolina-Molina (2018), Casanova (2020), Foucault (2002), Salazar (2020), UNESCO (2020), se desarrolló un abordaje metodológico documental-hermenéutico. Los resultados de la hermeneusis revelan que a finales de 2020 , es posible identificar reconfiguraciones globales que mediadas por la pandemia, vislumbran la edificación de un nuevo orden mundial de consolidación del capitalismo tecno-financiero, las tecnologías de la información y la comunicación se apoderan de las relaciones sociales, sustituyendo, subordinando, influyendo, condicionando, creando la subjetividad necesaria a la nueva normalidad, mientras se confirma una afectación de la pandemia con mayor severidad en los sectores más vulnerables de la población, la profundización de las desigualdades sociales, el desmantelamiento de la función pública y la ausencia progresiva del Estado en la atención de los problemas colectivos, siendo la salud y la educación dos de los sectores más afectados.

Palabras clave: nueva normalidad; COVID-19; América Latina; nuevo orden mundial; salud; educación.

\footnotetext{
* Economista. Magíster en Gerencia de Empresas. Dra. en Ciencias Sociales. Universidad del Zulia (LUZ). Profesora titular de la Facultad de Ciencias Económicas y Sociales (FCES). Coordinadora Académica del Doctorado en Ciencias Sociales Mención Gerencia de LUZ. Investigadora adscrita al Centro de Estudios de la Empresa de FCES-LUZ. E-mail: acunamarianela@fces.luz.edu.ve
} 


\title{
Latin America. Between the New reality and the old inequalities
}

\begin{abstract}
Dialogue among those of us who do academic life, share thoughts and actions, is always an exercise in spiritual recreation, rather than qualifying ourselves intellectually, it compromises our understanding of the common ethos. With this intention, the reflections of this work are proposed. Its objective is to recognize the new meanings that define contemporary reality in the context of the global pandemic of COVID-19, with an analytical emphasis on Latin America, its inequalities and the effects on health and education. Based on Álvarez, (2020), Bonilla-Molina (2018), Casanova (2020), Foucault (2002), Salazar (2020), UNESCO (2020), a documentaryhermeneutical methodological approach was developed. The results of the hermeneusis reveal that by the end of 2020 it is possible to identify global reconfigurations that, mediated by the pandemic, envision the construction of a new world order of consolidation of techno-financial capitalism, information and communication technologies take over the social relations, substituting, subordinating, influencing, conditioning, creating the necessary subjectivity to the new normal, while confirming a more severe impact of the pandemic in the most vulnerable sectors of the population, the deepening of social inequalities, the dismantling of the public function and the progressive absence of the State in the attention of collective problems, with health and education being two of the most affected sectors.
\end{abstract}

Keywords: new normal; COVID-19; Latin America; new world order; health; education.

\section{Introducción}

Las convocatorias a pensar el mundo y en particular América Latina al inicio de 2020, no imaginaron nunca el desafío que impondría un año de encuentros con la introspección, preñada de miedos y desconciertos que poco a poco fue mutando en retos, descubrimientos, adecuaciones, encuentros y "nueva normalidad".

En los diversos espacios, hoy múltiples casi inabarcables, de amigos, colegas, redes sociales, la comunicación, el diálogo reflexivo, compartido primero desde la humanidad intervenida de cada uno, pasando por la necesidad de comprensión de los nuevos sentidos y subjetividades en transformación, se expresa la intencionalidad del posicionamiento de una cosmovisión que, resignificando viejos y ya experimentados procesos de mediación y dominación, facilitados por el confinamiento, las redes de comunicación, el teletrabajo, la virtualización de la educación, viabilice la reconfiguración en marcha de la globalización.

La aparición de una pandemia global, en un escenario mundial que desmanteló sus servicios públicos de salud, mostró durante todo el año el efecto de la privatización de lo público, con consecuencias de muerte solo reconocidas en las guerras. Los países considerados más desarrollados, de liderazgo económico, militar y tecno-científico, pasaron a ser líderes en contagios, muertos, fosas comunes, y sistemas de salud colapsados. EEUU, hegemón geopolítico, es igualmente primero en COVID-19, acompañado de la Europa ilustrada, exhiben el fracaso de subordinar la vida a la mercantilización.

Otro tanto correspondió al mundo marginado de la floreciente globalización, en particular a América Latina, en la ruta de expansión de la pandemia, se relocalizó en Suramérica primero, para abarcar sucesivamente todo el espacio regional con profundas heridas 
especialmente en los siempre marginados, para los que, hasta hoy el debate permanente frente a las carencias y la muerte, solo tiene un nuevo actor el COVID-19.

Transcurridos ocho meses de haberse decretado la pandemia mundial por la Organización Mundial de la Salud (OMS), lo que se pensó temporal, superable en corto plazo, se instaló sin aún conseguir un trazado en las certidumbres a las que nuestro pensamiento se ajusta, con nuevos modos de conocernos y reconocernos, en el contexto de la adopción de mecanismos de intervención en todos los órdenes de la vida, para situar en el imaginario colectivo la noción de una "nueva normalidad", como afirma Valdettaro (2020), el COVID-19 colocó, de repente, a la humanidad en esa frontera siempre inestable entre naturaleza, biología y cultura que nuestro inocente imaginario cientificista suponía controlada.

Dialogar entre los que hacemos vida académica, compartimos pensares y haceres, es siempre un ejercicio de recreación espiritual, más que calificarnos intelectualmente, nos compromete la comprensión del ethos común. Con esa intención se proponen las reflexiones de este trabajo, para lo que se realizó una revisión documental de publicaciones correspondientes en su mayoría al año 2020, fundamentalmente producidas por instituciones académicas y científicos sociales motivados por debatir la incidencia de la nueva normalidad, a los efectos fueron analizadas dieciocho (18) producciones bibliográficas atendiendo al criterio de proposición teórico-documental correspondiente al período de aparición de la pandemia COVID19.

\section{Reconfiguraciones en marcha. Disciplinamiento estatal, anomia comunicacional y confinamiento}

A finales de 2020, es posible identificar reconfiguraciones del orden mundial que mediadas por la pandemia, vislumbran la edificación de un nuevo orden mundial de consolidación del capitalismo tecno-financiero liderado por grandes corporaciones vinculadas a la tecnología de las comunicaciones, el consumo virtualizado y las finanzas. El dominio del espacio económico, permea la definición política del orden global, y a la concentración corporativa le soporta un concierto político supranacional que disciplina desde la política pública la construcción crítica de la vida social. Para Torres (2020), "Ios indicadores centrales de la peligrosidad real del Covid-19, están ligados a su capacidad de matar seres humanos a partir del contagio y, de modo indirecto, a su capacidad de destruir las economías nacionales". Sostiene este autor que lo importante es determinar "respecto a qué cuestión resulta más impactante y urgente atender, si el volumen de mortalidad directa o el efecto de devastación de las economías, se está saldando a favor de la primera".

Son conocidas las intenciones corporativas de un reordenamiento global fundado en la tentación Malthusiana del control poblacional. De acuerdo a Salazar (2020):

"La pandemia es el ensayo de mayor envergadura que los barones del dinero y orientadores del Orden Internacional han instrumentado después de la segunda guerra mundial, cuyos preparativos devienen desde la última década del siglo XX, con el célebre discurso de John $\mathrm{D}$. Rockefeller III en la ONU, haciendo énfasis en la imperiosa necesidad de reducir la población, bajar significativamente los costos de atención a la salud y eliminar las ayudas a las familias numerosas y en situación económica desventajosa. 
En 2015, Bill Gate lo reafirmó y en septiembre de 2019 en una serie Netflix lo divulga masivamente, con la aseveración, si el H1NI provocó 575.400 muertes, este virus será de mayor registro de defunciones". (p.103)

La globalización como fenómeno civilizatorio idealizado desde su conceptualización economicista se redimensiona, y a los fenómenos de la concentración de capital geolocalizada, se adiciona la maximización de uso de las tecnociencias, con sus virtudes de reducción de costos, maximización de productividad y disolución del nexo sociocultural. El éxito de la novedosa organización global, demanda igualmente nueva institucionalidad, no por su emergencia inédita, más bien por el direccionamiento estratégico de sus fines y la posibilidad cierta de aprovechar la coyuntura sanitaria para consolidar nuevas relaciones sociales.

Particularmente desde su condición disciplinadora en la perspectiva de Foucault (2002) que trata de establecer las presencias y las ausencias, de saber dónde y cómo encontrar a los individuos, instaurar las comunicaciones útiles, interrumpir las que no lo son, poder en cada instante vigilar la conducta de cada cual, apreciarla, sancionarla, medir las cualidades o los méritos, como procedimiento para conocer, para dominar y para utilizar, ya no es condición exclusivamente administrada por las fuerzas del mercado, en la circunstancia actual la construye el miedo, la muerte, la disolución de los sistemas de salud pública, el Estado mínimo y la deshumanización hacia la virtualidad. Torres (2020), lo explica argumentando:

"De este modo, lo que acompaña la progresión mundial del COVID-19 es un temor societal creciente, magnificado por los medios de comunicación y cimentado por el discurso de la guerra de los estados protectores, que viene moldeando los comportamientos sociales de las grandes mayorías en el planeta. Es la primera vez en la historia de la humanidad que un flujo de temor colectivo prolifera, circula y se retroalimenta a un ritmo tan acelerado, a una escala plenamente mundial y a nivel de generalidad tan acabado". (p. 12)

Como en cada momento de crisis del orden mundial, ya sea las originadas en sus propias contradicciones, o las construidas para producir los quiebres necesarios y estratégicamente planificados, se recurre al Estado para la labor de disciplinar. El Estado mínimo que libera la economía, se hace máximo para garantizar el confinamiento, el teletrabajo, la prohibición del encuentro público, la penalización de la protesta ${ }^{1}$. En este sentido BrachetMárquez (2020) señala:

"El Estado es hoy el actor institucional al cual se le exige resolver la situación catastrófica del contagio masivo del Covid-19 pero, en condiciones infraestructurales y medios presupuestales débiles, mientras que la iniciativa privada adopta un perfil bajo en un escenario que, por el momento, representa pocas posibilidades de acciones redituables". (p. 26)

Explica Bonilla-Molina (2018), que una sociedad que no tiene lugares de encuentro para aprender a vivir, a convivir, a trabajar juntos, es una no-sociedad, se pretende confinar a los individuos a espacios cada más reducidos y localizados, con la menor inversión social, 
sustituyendo el encuentro humano por la virtualidad, como parte de un nuevo modelo de producción, consumo de mercancías y educación en el marco de un modelo de gobernanza mundial del capitalismo globalizado.

El desarrollo vertiginoso de las tecnologías de la información y la comunicación se apoderan de las relaciones sociales, sustituyendo, subordinando, influyendo, condicionando, creando la subjetividad necesaria a la nueva normalidad, en palabras de Zebadúa (2020), el uso de la tecnología digital con fines de control social será el mayor logro inducido en esta fase dirigido por los medios masivos digitales, cuyas funciones abarcan la penetración, vigilancia, monitoreo de millones de usuarios para gestionar gustos, tendencias conductas, necesidades, ocio, entretenimiento, en suma todo el espectro de la vida humana.

Según el autor in comento, la ciudadanía digital en formación comparte otro proyecto derivado de la fase tecnológica en curso (robótica, inteligencia artificial) que se instala en lo militar -armamento supersónico velocidad match 20-, las comunicaciones -telefonía, el comercio -múltiples compras en línea, Amazon-, el entretenimiento -neflix-, la banca -múltiples páginas de servicios, tarjetas de crédito-, la educación -videoconferencias, zoom, entre otros.

Hacer global un nuevo imaginario se asienta en el poder de los medios masivos de comunicación con las redes sociales como protagonistas, la construcción de símbolos, identidades, significados y realidades ahora con magnificación virtual, diluyen la aproximación a lo cotidiano, cercenan el reconocimiento de lo propio y universalizan problemas, desafíos y respuestas. Los medios masivos satisfacen una sensación de simultaneidad entre las necesidades de la vida y el acceso a la información, rompiendo la condición del confinamiento en un espacio artificialmente concebido para una movilidad-libertad que recrea la ilusión sentida como realidad, de la interacción social.

La comunicación virtual desdibuja las fronteras del hogar, lo convierte en espacio de trabajo, unifica el espacio vital del encuentro afectivo con la responsabilidad laboral, enajena en una obligada presencia colectiva, que al tiempo es ausente. Parece necesario convencer a todos que la mediación de subsistencia es el trabajo sin fin, y que solo a través del ejercicio permanente expuesto en el ciberespacio, es posible la existencia humana. Confinamiento disciplinado y comunicacionalmente dirigido avizora ser la clave de la nueva normalidad.

\section{América Latina. Desigualdades en tensión heredadas a la pandemia}

La región latinoamericana ha sido de las más afectadas por la pandemia, la intensidad del contagio y su corolario de muertes, develo la debilidad estructural de sus sistemas de salud, afectada por años de desinversión pública y privatizaciones. Desde México hasta Argentina se cuentan por miles, los enfermos y fallecidos, Ecuador, Perú, Brasil, Colombia, Argentina y México, registran los mayores índices.

Ante la pandemia, diversas resultaron las políticas públicas de atención al desconcertante y sorpresivo evento, transitando desde una descalificación de su importancia hasta la intervención preventiva y recurrente para minimizar la trasmisión colectiva creciente. Igualmente, diferenciadas son las afectaciones de la enfermedad, se dice democrático el virus, porque todo humano es susceptible a padecerlo, pero lo real es que unas condiciones preexistentes asociadas a la cualidad social de los afectados determinan en quienes recae el mayor contagio. Señala López (2020): 
"el virus es igualitario -se prende a todo cuerpo- pero sus efectos se cumplen diferencialmente en un orden de desigualdades. No sólo las consabidas de edad 0 enfermedades preexistentes que lo vuelven riesgoso para la continuidad de la vida. También desigualdades sociales, de clase y de género. La masividad del peligro pone en evidencia los desiguales accesos a la salud" (p. 170)

En el que es señalado como el continente más desigual del mundo, vimos la precarización de la salud, como la primera emergencia, para ir redescubriendo carencias, y cuando el confinamiento se hizo rutina de vida, la necesidad de pensar la educación para garantizar su continuidad, se situó como un segundo desafío a resolver, en este sentido De la Cruz Flores (2020) afirma:

"El COVID-19 derrumbo las certezas en el ámbito educativo, induciendo

a crear alternativas en un afán desesperado por contener estructuras colapsadas que, desde hace tiempo, y de manera sistemática e insidiosa, han sido desmanteladas, y con ellas, los servicios públicos y de bienestar común". (p. 46)

Una de las revelaciones de la pandemia ha sido la confirmación del desmantelamiento de la función pública, y la ausencia progresiva del Estado en la atención de los problemas colectivos, afectación manifiesta en la carencia de un sistema público de salud capaz de responder eficientemente a la creciente demanda de atención sanitaria generada por el COVID19, así como las urgentes medidas de reconversión de los métodos para impartir educación a distancia ante la necesaria sustitución de la educación presencial limitada por el confinamiento de la población.

La educación es uno de los ámbitos de mayor afectación y consecuencias de la pandemia, no porque ella causara los problemas estructurales que enfrenta el sector educativo, y que son objeto de análisis y políticas institucionales permanentes cuya representación global está en la Organización de las Naciones Unidas para la Educación, la Ciencia y la Cultura (UNESCO, 2020), sino más bien porque desveló las limitaciones de la praxis educativa y las narrativas que justifican su funcionamiento articulado a las necesidades del sistema mundo (Acuña y Sánchez, 2020).

Mientras un discurso de carácter instrumental define una educación de calidad y excelencia, la educación se sitúa frente al desafío de inequidades sociales convertidas en brechas económica, de género, de origen y tecnológicas. Así la pobreza, la condición femenina, la ubicación en el espacio rural o urbano, la disponibilidad y conocimiento de tecnologías de la información y la comunicación, constituyen determinantes en la educación pospandemia.

La educación, está vinculada a la naturaleza, las instituciones, la política, la economía y el trabajo, es un ámbito intrínsecamente social y un campo de praxis en el que se construyen valores, se constituyen mecanismos de socialización y se transmiten contenidos que contribuyen a la formación de los sujetos para su desarrollo individual, la vida colectiva y el trabajo (Casanova, 2020).

Las reconfiguraciones de la educación mediadas por la pandemia del COVID-19, tienen dos miradas, una institucional de pretendida instauración universal, cuya apreciación es 
la adecuación de la educación a las tecnologías de la información y la comunicación para reconstituir en la virtualidad los espacios de la educación presencial, y otra más compleja que sitúa el hecho educativo en el contexto social prepandemia y resignifica sus sentidos para evitar la trampa tecnológica como única e irreversible solución al futuro de la educación (Acuña y Sánchez, 2020).

Históricamente, la educación se ha enfrentado al desafío de la incorporación de la tecnología como mediadora del proceso enseñanza-aprendizaje, así en un recorrido evolutivo como es señalado por el Centro de Pensamiento en Políticas Públicas de Educación Superior de la Universidad Nacional de Colombia (2020), se introducen diversas herramientas de tecnología educativa entre las que se cuentan, los audiovisuales (radio y televisión educativas), la digitalización y los multimedia y más recientemente la educación virtual.

De acuerdo a lo expuesto, es posible observar que unos grupos sociales están en capacidad de migrar de la educación presencial hacia la educación virtual, por ubicarse entre los estratos de mayor nivel socioeconómico, con la acceso a internet, redes virtuales e infraestructura de conectividad permanente, mientras otros grupos sociales, marginados del acceso al goce efectivo del derecho a la educación ven aumentar las desigualdades socioculturales entre quienes tienen acceso a internet y quienes no, y deben conformarse con las tecnologías educativas que se ofrecían en los años sesenta del siglo XX: la radio y la televisión.

Considerando la idea de Didriksson (2020), la crisis tiene mayor afectación sobre los pobres, los trabajadores sin protección laboral ni cobertura de seguridad social, situación que se traslada al ámbito de la educación, estudiantes sin computadora o que sus teléfonos móviles no tienen el crédito suficiente para tomar las horas de clase que les están imponiendo, situaciones que obligan a definir como el eje central de la política pública la atención de la salud y la educación.

En América Latina, debe adicionarse al análisis referido la circunstancia de inequidad en la disponibilidad de servicios básicos como electricidad, telecomunicaciones, transporte y bioseguridad, visible entre lo urbano y lo rural, o entre los diferentes estratos socioeconómicos, lo que demuestra que no existen condiciones para promover y garantizar la calidad en la prestación del servicio educativo en la modalidad de educación virtual, para cumplir con sus funciones educativas.

En el modelo de gobernanza globalizado, es necesario cuestionar la educación como parte de un nuevo modelo de producción, consumo de mercancías y educación en el presente siglo, usando la casa, el hogar, como epicentro de este reordenamiento. En el contexto referido, la pandemia COVID-19, permite reafirmar la tendencia a concentrar a los individuos en espacios cada vez más reducidos y localizados, con la menor inversión social. La privatización de la educación superior y su corolario en la desinversión pública en universidades, instituciones de investigación y políticas de promoción de investigación y desarrollo, coinciden con la discursiva actual de educación virtual fundada en las TICS y el autoaprendizaje socialmente descontextualizado. Expresa Álvarez (2020):

"La educación a distancia profundizará las brechas, no solo porque ellas existen desde antes de la Pandemia, también porque la educación hace más diseños para los mejores, es disciplinada por las evaluaciones, asediada por la pérdida de la gratuidad, y su privatización y 
mercantilización están unidas al capitalismo digital. Por consiguiente, la educación retornara al destino del que se quiso separar, incluso por el relato antipedagógico de las neurociencias y de la inteligencia artificial que pretende hacernos creer que ya no necesitamos pensar, cuando olvida algo fundamental y que la inteligencia es un asunto biológico tal como lo señala Markus Gabriel.(2016)". (p. 15)

El reto que debe conducir la misión y el sentido de la educación superior será lograr la formación de ciudadanos éticos, solidarios, colaborativos, comprometidos con el planeta, en una sociedad globalizada, capaces de enfrentar la incertidumbre. La educación como proceso social se hace pertinente en la construcción de los imaginarios y el conocimiento transformador, la contribución científico-técnica a la continuidad de la educación es importante pero no suficiente, las condiciones de la vida humana en todos los órdenes, material y espiritual, individual y colectiva, determinan la relación cognoscente y las subjetividades mediadas por la educación, abstraerse de esa realidad vacía de contenido el rol edificador de la educación.

En el caso de la educación universitaria, los condicionantes expuestos tienen afectación directa sobre los actores del sistema de educación superior. Estudiantes, docentes e Instituciones de Educación Superior (IES), son receptores del impacto que la coyuntura actual tendrá en la prosecución académica, la docencia y la sostenibilidad de la IES. Seguidamente en la Tabla No. 1, se presentan los efectos discriminados para cada segmento del proceso educativo.

Tabla No. 1

Impacto del COVID-19 en actores de la educación superior

\begin{tabular}{|l|l|l|}
\hline ACTORES & IMPACTO & CONSECUENCIA \\
\hline \multirow{5}{*}{ Estudiantes } & $\begin{array}{l}\text { Cese temporal de } \\
\text { actividades }\end{array}$ & $\begin{array}{l}\text { Abandono de los estudiantes más vulnerables } \\
\text { Inequidad en el ingreso a la educación superior }\end{array}$ \\
\cline { 2 - 4 } & $\begin{array}{l}\text { Incertidumbre en } \\
\text { continuidad de sus } \\
\text { aprendizajes }\end{array}$ & $\begin{array}{l}\text { Sustitución de las clases presenciales por educación } \\
\text { virtual }\end{array}$ \\
\cline { 2 - 4 } & $\begin{array}{l}\text { Desequilibrio } \\
\text { socioemocional }\end{array}$ & $\begin{array}{l}\text { Ansiedad y depresión } \\
\text { Alteración de rutinas de socialización }\end{array}$ \\
\cline { 2 - 4 } & Incremento de costos & $\begin{array}{l}\text { Suspensión de beneficios mientras estudian a } \\
\text { distancia } \\
\text { Continuidad de pago de préstamos y créditos } \\
\text { universitarios } \\
\text { Mercado laboral deprimido por causa de la crisis }\end{array}$ \\
\cline { 2 - 4 } & $\begin{array}{l}\text { Cambio de modalidad } \\
\text { presencial a distancia }\end{array}$ & $\begin{array}{l}\text { Poca aceptación pregrado } \\
\text { Mayor aceptación posgrado } \\
\text { Mayor disciplina y compromiso para aprendizaje }\end{array}$ \\
\cline { 2 - 4 } & Movilidad internacional & $\begin{array}{l}\text { Suspensión total primer semestre 2020 } \\
\text { Incertidumbre segundo semestre 2020 }\end{array}$ \\
\hline & Estabilidad laboral & $\begin{array}{l}\text { Reducción de contratación temporal } \\
\text { Despidos o reducciones de beneficios salariales }\end{array}$ \\
\hline
\end{tabular}




\begin{tabular}{|c|c|c|}
\hline \multirow{4}{*}{ Docentes } & $\begin{array}{l}\text { Continuidad de la } \\
\text { actividad docente bajo la } \\
\text { modalidad virtual }\end{array}$ & $\begin{array}{l}\text { Adecuación tecnológica para la educación a distancia } \\
\text { Efectos diferenciales dentro de cada universidad y a } \\
\text { escala sistémica } \\
\text { Diferenciación de calidad educativa por TICS } \\
\text { Requerimientos de cursos de capacitación para } \\
\text { atención de la curva de aprendizaje para la utilización } \\
\text { eficiente de la tecnología en educación superior a } \\
\text { distancia con apoyo tecnológico y pedagógico }\end{array}$ \\
\hline & Riesgo de brecha digital & $\begin{array}{l}\text { Dispar manejo de la virtualidad, en lo que se refiere al } \\
\text { manejo de las distintas herramientas tecnológicas y de } \\
\text { soportes (infraestructura adecuada, tanto en apps y } \\
\text { plataformas) necesarios para orientar procesos de } \\
\text { aprendizaje a distancia mediados por las tecnologías. } \\
\text { Diversidad de acceso a la conectividad (disposición de } \\
\text { servidores adecuados a la carga de trabajo telemática } \\
\text { exigida y disposición del ancho de banda necesario } \\
\text { para conectarse, entre otros aspectos) para que el } \\
\text { proceso de enseñanza aprendizaje en línea fluya de } \\
\text { manera efectiva. } \\
\text { Necesidad de ofrecer alternativas de atención a } \\
\text { alumnos que no cuenten con las herramientas } \\
\text { necesarias para recibir el servicio virtualizado } \\
\text { (soluciones tecnológicas y contenidos para su uso en } \\
\text { teléfonos móviles). }\end{array}$ \\
\hline & $\begin{array}{l}\text { Investigación y extensión } \\
\text { universitaria }\end{array}$ & $\begin{array}{l}\text { Suspendidas temporalmente, continuidad solo aquella } \\
\text { de base bibliográfica. }\end{array}$ \\
\hline & $\begin{array}{l}\text { Personal no docente } \\
\text { (apoyo administrativo) }\end{array}$ & $\begin{array}{l}\text { Reducción de puestos de trabajo. } \\
\text { Restricciones financieras debido a la disminución de } \\
\text { aranceles o de matrículas estudiantiles. }\end{array}$ \\
\hline \multirow[b]{2}{*}{ IES } & Viabilidad académica & $\begin{array}{l}\text { Adecuación a modalidad virtual } \\
\text { Capacidad de respuesta a necesidades técnicas y } \\
\text { tecnológicas para toda la educación que imparte la IES }\end{array}$ \\
\hline & Sostenibilidad financiera & $\begin{array}{l}\text { Dificultades financieras por restricciones de aportes } \\
\text { públicos (recortes importantes en la inversión pública } \\
\text { en educación). } \\
\text { Dificultades financieras por reducción de matrícula y } \\
\text { aranceles. } \\
\text { Disminución de la demanda del servicio educativo por } \\
\text { crisis económica. }\end{array}$ \\
\hline
\end{tabular}

Fuente: elaboración propia con base en UNESCO-IESALC (2020).

Según Vázquez y Vommaro (2020), la pandemia transformó las relaciones entre lo público y lo privado como conceptos y como prácticas sociales. La revalorización de lo público estatal se manifestó en el valor social que se les otorgó a las tareas de cuidados, educativas, de salud y de producción del conocimiento científico, resignificó la centralidad de la regulación estatal en la gestión de los servicios considerados prioritarios en tiempos excepcionales (acceso a telefonía, internet y televisión como servicios públicos) y transformó la visión individualista (consumidor-cliente) desde la cual este tipo de consumos suelen ser pensados. Los efectos de 
la pandemia exacerbaron las desigualdades, emergentes y preexistentes, trasladando al espacio público las posibles salidas a la crisis con dos visiones en disputa, un cauce colectivo mediado por lo público y otra individualista, pensada como el derecho a tener derechos siempre individuales.

La respuesta política de los países ante la pandemia COVID-19, se ha dirigido a medidas administrativas para la salvaguarda del funcionamiento del sistema; recursos financieros; y la disposición de recursos para dar continuidad a las actividades formativas. Las respuestas institucionales han cubierto, desde el primer momento, distintos ámbitos: el frente estrictamente sanitario, el ajuste de los calendarios, la contribución desde la investigación y el desarrollo a mitigar la pandemia, la garantía de continuidad de actividades formativas por medio de la educación a distancia, y el apoyo en recursos bibliográficos y tecnológicos y también socioemocional a la comunidad universitaria UNESCO-IESALC (2020).

Si bien es importante que exista una estrategia global para la educación superior en el nuevo escenario mundial, se requiere reflexionar sobre sus sustratos y propósitos, y cuestionar el rol de los actores institucionales para propiciar miradas alternativas constitutivas de las realidades del mundo marginado de los beneficios formalmente declarados de la virtualización de la educación, para que sea reconocida la necesidad de una educación pertinente vinculada a la cultura de cada sociedad, sus capacidades y sus desafíos.

\section{Conclusiones}

Pensar el mundo y en particular América Latina durante el año 2020, es un encuentro con la introspección, preñada de miedos y desconciertos que poco a poco fue mutando en retos, descubrimientos, adecuaciones y significados. Transcurridos ocho meses de haberse decretado la pandemia mundial por la Organización Mundial de la Salud (OMS), lo que se pensó temporal, superable en corto plazo, se instaló sin aún conseguir un trazado en las certidumbres a las que nuestro pensamiento se ajusta, con nuevos modos de conocernos y reconocernos, en el contexto de la adopción de mecanismos de intervención en todos los órdenes de la vida, para situar en el imaginario colectivo la noción de una "nueva normalidad".

A finales de 2020, es posible identificar reconfiguraciones del orden mundial que mediadas por la pandemia, vislumbran la edificación de un nuevo orden mundial de consolidación del capitalismo tecno-financiero liderado por grandes corporaciones vinculadas a la tecnología de las comunicaciones, el consumo virtualizado y las finanzas. El dominio del espacio económico, permea la definición política del orden global, y a la concentración corporativa le soporta un concierto político supranacional que disciplina desde la política pública la construcción crítica de la vida social. El desarrollo vertiginoso de las tecnologías de la información y la comunicación se apoderan de las relaciones sociales, sustituyendo, subordinando, influyendo, condicionando, creando la subjetividad necesaria a la nueva normalidad

La región latinoamericana ha sido de las más afectadas por la pandemia, la intensidad del contagio y su corolario de muertes, develo la debilidad estructural de sus sistemas de salud, afectada por años de desinversión pública y privatizaciones Una de las revelaciones de la pandemia ha sido la confirmación del desmantelamiento de la función pública, y la ausencia progresiva del Estado en la atención de los problemas colectivos La educación es uno de los ámbitos de mayor afectación y consecuencias de la pandemia. Los efectos de la pandemia sobre 
la educación hicieron emerger las limitaciones de la praxis educativa y las narrativas que justifican su funcionamiento articulado a las necesidades del sistema mundo, identificándose efectos disruptivos sobre su funcionamiento y las capacidades de adaptación a la nueva realidad pospandemia.

La educación como proceso social, se hace pertinente en la construcción de los imaginarios y el conocimiento transformador, la contribución científico-técnica a la continuidad de la educación es importante pero no suficiente, las condiciones de la vida humana en todos los órdenes, material y espiritual, individual y colectiva, determinan la relación cognoscente y las subjetividades mediadas por la educación, abstraerse de esa realidad vacía de contenido el rol edificador de la educación.

\section{Referencias bibliográficas}

Acuña Ortigoza, Marianela y Sánchez Acuña, Carla. (2020). Educación Superior pospandemia. Las asimetrías de la brecha tecnológica. Revista Venezolana de Gerencia (RVG). Año 25 No. 92. Venezuela. pp.1282-1287.

Álvarez, Freddy (2020). Universidad y pandemia. Pensar la pandemia. Observatorio social del coronavirus. CLACSO. Argentina.

Bonilla-Molina-Molina, Luis (2018). Apagón Pedagógico Global. Las instituciones educativas en la cuarta revolución industrial y la era de la singularidad. Extraído de https://centrodeinvestigacionclacsoriusmex.files.wordpress.com/2019/04/apagocc81n -pedagocc81gico-global.pdf.

Brachet-Márquez, Viviane (2020). El Covid-19 desde una perspectiva histórica. Teoría \& cambio social La nueva América Latina. No.1. CLACSO. Argentina.

Casanova Cardiel, Hugo (2020). Educación y pandemia: el futuro que vendrá. IISUE (2020). Educación y pandemia. Una visión académica. UNAM. México.

Centro de Pensamiento en Políticas Públicas de Educación Superior (2020). Pospandemia en educación superior: retos, crisis y promesas. No. 226. Universidad Nacional de Colombia. Colombia.

De la Cruz Flores, Gabriela (2020). Certezas e incertidumbres. Educación. Espejismos y faros en tiempos de COVID-19. Perfiles Educativos. IISUE-UNAM. Vol. XLII, núm. 170. México. Pp.46/53. Extraído de http://www.iisue.unam.mx/perfiles/articulo/2020-170-laeducacion-entre-la-covid-19-y-el-emerger-de-la-nueva-normalidad.pdf

Didriksson T., Axel (2020). Ante la pandemia, evitar reproducir la desigualdad social y educativa.

Educación y pandemia. Una visión académica. IISUE (2020). UNAM. México.

Foucault, Michel (2002). Vigilar y castigar: nacimiento de la prisión. Siglo XXI Editores. Buenos Aires. Argentina.

López, María Pía (2020). El futuro ¿ya llegó? en Argentina futura. Jefatura de Gabinete de Ministros. El futuro después del COVID-19.Edición Argentina Unida. Argentina. Extraido

https://www.argentina.gob.ar/sites/default/files/el_futuro_despues_del_covid-19_0.pdf Salazar, Robinson (2020). Cinco premisas sobre la pandemia y su vínculo con el nuevo orden mundial en Salazar, Robinson y Roncal, Ximena. América Latina después del 2020. Colección Insumisos Latinoamericanos. Argentina. 
Torres, Esteban (2020). Covid-19 (I): La autoconservación social (2020). Teoría \& cambio social. La nueva América Latina. CLACSO. Argentina. Extraído de https://www.clacso.org/covid-19-como-explicar-lo-que-esta-pasando-i-la-autoconservacion-social/

UNESCO (2020). El coronavirus covid-19 y la educación superior: impacto y recomendaciones. Extraído de https://www.iesalc.unesco.org/2020/04/02/elcoronavirus-covid-19-y-laeducacion-superior-impacto-yrecomendaciones/.

UNESCO-IESALC (2020). COVID-19 y educación superior: De los efectos inmediatos al día después. Análisis de impactos, respuestas políticas y recomendaciones. Extraído de https://es.unesco.org/covid19/globaleducationcoalition

Valdettaro, Sandra (2020). El virus es el mensaje en Argentina futura. Jefatura de Gabinete de Ministros. El futuro después del COVID-19. Edición Argentina Unida. Argentina. Extraido

https://www.argentina.gob.ar/sites/default/files/el futuro despues_del_covid-19_0.pdf

Vázquez, Melina y Vommaro, Pablo (2020). Jóvenes y reconfiguraciones de lo público: lecturas desde la pandemia. Pensar la pandemia. Observatorio social del coronavirus. CLACSO. Argentina. Extraído de https://www.clacso.org/en/jovenes-yreconfiguraciones-de-lo-publico-lecturas-desde-la-pandemial

Zebadúa, Miguel Ángel (2020). De ciudadanos a usuarios, algunos impactos de la pandemia en Salazar, Robinson y Roncal, Ximena. América Latina después del 2020. Colección Insumisos Latinoamericanos. Argentina. 